\title{
Overview of the Greater Lyon weather radar advances from 90's to 2008
}

\author{
F. Renard and J. Comby \\ UMR 5600 Environnement Ville Société CNRS, Lyon, France
}

Received: 29 October 2009 - Revised: 8 February 2010 - Accepted: 14 February 2010 - Published: 16 March 2010

\begin{abstract}
The local weather radar of Lyon, part of the Aramis network of Meteo-France, is currently located $40 \mathrm{~km}$ from the urban community. The measurement quality of this tool is subjected to constant improvements from MeteoFrance. Indeed, its hydrological measurement quality has steadily evolved from the early 90 's until today. This article, therefore, proposes a return on these innovations, assessing measurement quality over the territory of Greater Lyon. This study is based on two successive radar locations, and also on raw reflectivity data and on rain accumulation over the past $15 \mathrm{~min}$ (Hydram) or $5 \mathrm{~min}$ (Panthere). The measurement performed on the site Satolas was unsatisfactory because of too many ground clutters; and therefore the radar was moved to Saint-Nizier. This new location associated with radar $\mathrm{Hy}$ dram rain accumulation has reduced the problem of ground clutters. These rain accumulation data have given correct results in comparison with local data of the raingauge network of Greater Lyon, after a global and spatially uniform correction, based on these gauges. The latest generation of radar rain accumulation (Panthere) has, nearly completely, eliminated the problem of ground clutter in the urban area and provides very satisfactory measurements, especially during intense rain events.
\end{abstract}

\section{Introduction}

The urban community of Lyon, with 1.2 million inhabitants, contains strong human, environmental and material stakes. Many hazards of different origin may affect them (Renard and Chapon, 2010). One of the greatest hazards concerning

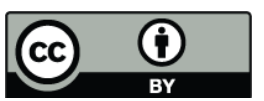

Correspondence to: F. Renard (frenard@grandlyon.org) managers and elected officials of that territory is rainfall, especially exceptional intense episodes. Thus, improving the knowledge of rainfall is essential in such an area.

Many studies based on the exploitation of rainfall networks have been carried out (Renard and Comby, 2007), reinforced in recent years by advances in the measurement by weather radar (Chapon et al., 2008; Creutin et al., 2009; Delrieu et al., 2009). However, few studies have been conducted at the micro-local level of an urban area like Greater Lyon. The location of the local radar and its accuracy has greatly evolved from the early 90's until today. Consequently, the aim of this article is to present the evolution of the measurement quality of Lyon weather radar data over the territory's urban area.

The radar was installed in the early 90's on the site of the airport of Lyon-Satolas, east of Lyon. In early 2001, this Cband radar was moved to the town of St-Nizier d'Azergues, forty kilometers northwest of Lyon (Fig. 1). This work examines two types of data provided by Meteo-France (Michelson et al., 2005): data of radar reflectivity, close to the raw radar measurements, previously converted in rain intensity according to the Marshall-Palmer 1948 relation $\left(Z=200 R^{1.6}\right)$, and data of rain accumulation over the past 15 min (Hydram) or 5 min (Panthere) after corrections by Meteo-France.

This article describes the approach based on an evaluation by simulation and by use of real data for different locations and different data generations. These tests also identify the possible presence of ground clutters in the urban area. Finally, radar data are compared with values of rainfall measurement network of Greater Lyon, firstly by comparing the average surface accumulated precipitation, and then locally by vertically extracting the network measure values of Greater Lyon.

Published by Copernicus Publications on behalf of the European Geosciences Union. 




Fig. 1. Radar sites over the Greater Lyon.

\section{Analysis of the hydrological measurement quality of satolas radar: since the 90's to 2001}

When changing the location of the radar, DSO Meteo-France had conducted an analysis of quality measurement of the radar located in Lyon Satolas (Meteo-France, Direction des Systèmes d'Observation, 2001). This mapping of ground clutter and masks observed on radar images show that most of the Lyon area is affected by problems. This study is confirmed by the accumulation of radar reflectivity throughout the month of March 2001, which shows lots of significant ground clutters on the Greater Lyon topography. The accumulation of 22/09/1993 radar reflectivity images is very coherent with the results obtained by Meteo-France for March 2001. The location of ground clutters matches perfectly between the two results, and it is found that ground clutters strongly penalize the use of data over the Lyon area.

Several reasons are behind these limitations. The first is directly related to topography. The radar, located in the east plain of Lyon at an elevation of $250 \mathrm{~m}$, is too low to measure precipitation accurately. Indeed, with a beam elevation of only $0.4^{\circ}$, it hits Greater Lyon's topography, especially in the Northeast and West, which includes a highest peak at $626 \mathrm{~m}$ (Fig. 1). The second is related to the urban terrain, such as buildings or towers. The Minguette's district in Vénissieux, with it's tower blocks of about thirty meters height, or the Part-Dieu business area, with the tallest building rising to $164 \mathrm{~m}$ were very problematic. These natural and man made obstacles, that stopped the radar beam and created important masks downstream, led to the decision of moving the radar to a more favourable area in early 2001 . The radar is now located about forty kilometres northwest of Lyon, in the commune of Saint-Nizier-d'Azergues at an elevation of
$920 \mathrm{~m}$. It provides Hydram rain accumulation over the past 15 min until 2006, then Panthere rain accumulation over the past $5 \mathrm{~min}$, which, of course, is considered a lot more sophisticated.

\section{Analysis of the hydrologic measurement quality of saint-nizier radar: from 2001 to 2006 (reflectivity and hydram rain accumulation)}

\subsection{Evaluation by simulation}

The simulation procedure implementation takes precisely the approach described by Delrieu et al. (1995), Pellarin (2001) and Pellarin et al. (2002). Simulations can be decomposed into two stages: (a) corresponding to the simulation of ground clutters and masks generated by the terrain, and (b) the integration effects of the vertical structure of precipitation on the theoretical errors committed when estimating intensities rain on the ground. The application of this approach to the operational radar network ARAMIS is described in Faure (2005 and 2006). The simulations show that Greater Lyon and its surrounding areas are located within the zone of high visibility. Nevertheless, a significant number of pixels on the Greater Lyon should be impacted by some small ground clutter effect (Fig. 2).

\subsection{Evaluation by real data}

For the two types of data, forty rainy days within the period 2001-2005 were accumulated : 11329 images (1 image each $5 \mathrm{~min}$ ) for the data of radar reflectivity, and 3673 images for the Hydram rain accumulation (1 image each $15 \mathrm{~min}$ ) (Figs. 3 and 4). 


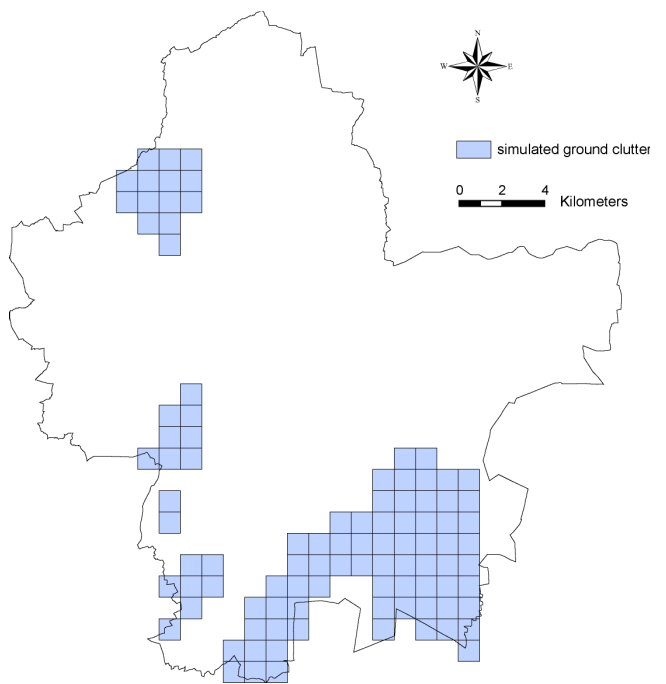

Fig. 2. Simulated ground clutters over the Greater Lyon, for the Hydram rain accumulation period (2001-2006)

There is very good consistency between the two types of rain accumulation and with simulation results. It thus confirms the areas within the Greater Lyon affected by ground clutter. The list of these pixels affected has been compiled, based on reflectivity accumulation, and were screened to compare local values of radar to rain gauge values of the area of Lyon (Fig. 1).

\subsection{Global surface comparison based on accumulated precipitation of rainfall event on the Greater Lyon (reflectivity and Hydram rain accumulation)}

Greater Lyon has a dense network for rainfall measurement: 29 rain gauges, which provide data each $6 \mathrm{~min}$ (Fig. 1). The average values of radar rainfall in the urban area (for both types of data) were calculated for the 17 rain events in the sample period from 2001 to 2005, and compared with average values of the 29 rain gauges from Greater Lyon. The differences between rain gauges values and radar data show high amplitude over time, especially for values of reflectivity. Thus, an overall factor based on the Greater Lyon rain gauges was assigned to radar data for each rainfall event in order to match the average rain gauges and radar rainfall accumulation. These radar data were then locally compared to the pluviometer values.

\subsection{Local comparison of radar data to rain gauge values (reflectivity and Hydram rain accumulation)}

Pixel values of the radar data are locally compared to the values of pluviometers associated with them, for all the rainfall events of the sample. A local extraction of radar values at the location of available rain gauges has been conducted.
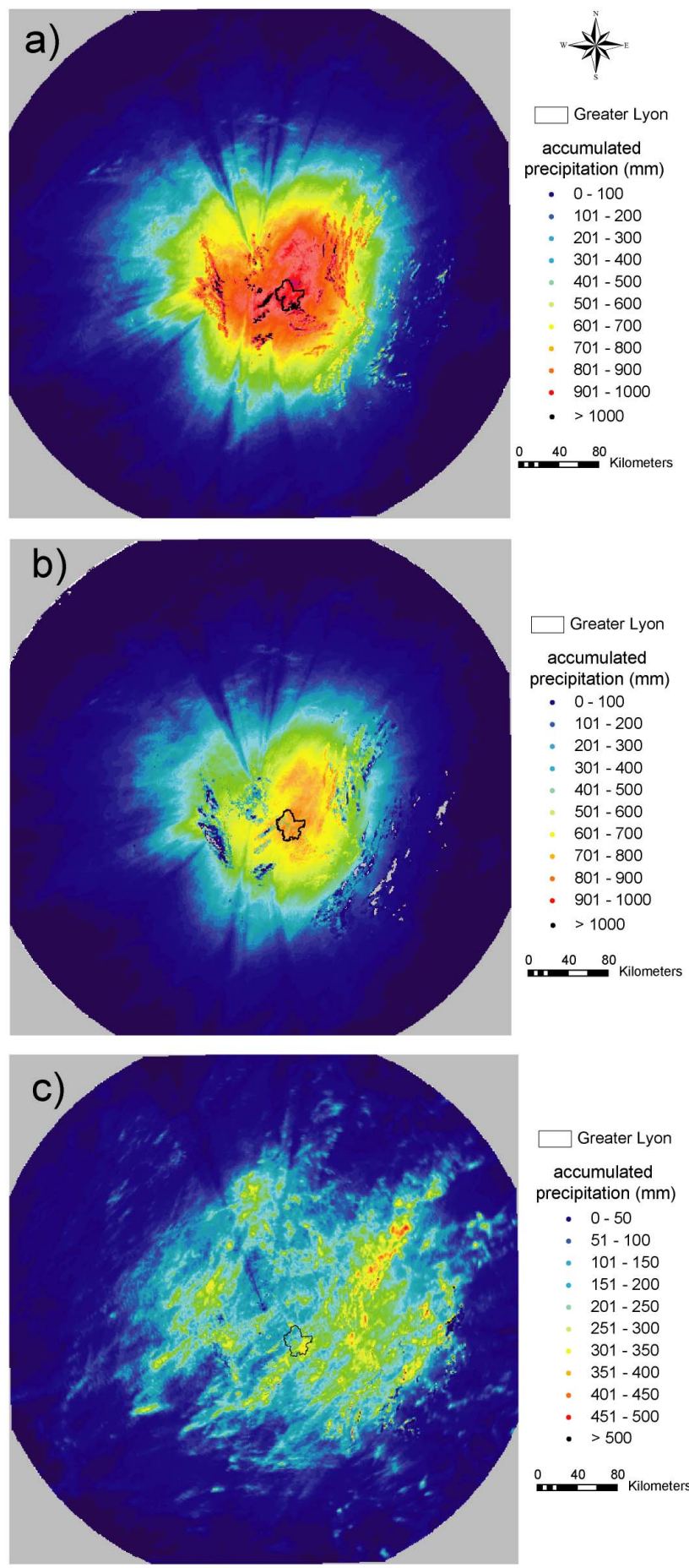

$\square$ Greater Lyon

accumulated precipitation $(\mathrm{mm})$

- $0-50$

- $51-100$

- $101-150$

- $151-200$

$201-250$

$251-300$

$301-350$

$351-400$

- $401-450$

- $451-500$

- $>500$

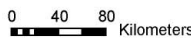

Fig. 3. a and b: accumulated precipitation of 17 rainfall events from July 2001 to July 2005 (a) 11329 reflectivity images converted with Marshall-Palmer, 1948; (b) 3673 Hydram rain accumulation images; (c) July 2008 accumulated precipitation for 8928 Panthere rain accumulation images. 
Table 1. Absolute and relative average differences between rain gauges and radar rain accumulation or radar reflectivity depending on the type of exceptional rain events (exceptional episodes in terms of intensity, accumulated precipitation or duration).

\begin{tabular}{lcccc}
\hline & & \multicolumn{2}{c}{ Type of exceptional rainfall events } \\
\hline Type of radar data & Average difference & $\begin{array}{c}\text { In terms of } \\
\text { intensity }\end{array}$ & $\begin{array}{c}\text { In terms of } \\
\text { accumulated } \\
\text { precipitation }\end{array}$ & $\begin{array}{c}\text { In terms of } \\
\text { duration }\end{array}$ \\
\hline Hydram & & & 8.2 & 7.0 \\
rain accumulation & Absolute $(\mathrm{mm})$ & 5.3 & 11.8 & 13.4 \\
Raw reflectivity & Relative $(\%)$ & 37.6 & 9.0 & 8.2 \\
(converted with Marshall-Palmer 1948) & Absolute $(\mathrm{mm})$ & 5.5 & 13.1 & 16.8 \\
$\begin{array}{l}\text { Panthere } \\
\text { rain accumulation }\end{array}$ & Relative $(\%)$ & 41.7 & & \\
\hline
\end{tabular}

From this comparison, it appears that the average difference between rainfall data and radar values is low $(20.4 \%$ for the radar rain accumulation and $23.3 \%$ for the reflectivity), and varies considerably depending on the type of rainfall event. Thus, if the average gap between radar rain accumulation and rain gauges water reached $37.6 \%$ in the case of exceptionally intense rainy episodes, it falls respectively to $11.8 \%$ and $13.4 \%$ in the case of exceptional events in terms of accumulated precipitation and in terms of duration, but without convective structure (Table 1).

\section{Analysis of the hydrologic measurement quality of saint-nizier radar: since 2006 (panthere rain accumulation)}

\subsection{Evaluation with real data}

This assessment of the Panthere rain accumulation over the past 5 min uses the same methodology as that used for the Hydram rain accumulation over the past $15 \mathrm{~min}$ : the accumulation of several rainfall episodes. Here, the entire month of July 2008 was accumulated, reaching $500 \mathrm{~mm}$ based on 8928 Panthere rain accumulation images. An improvement of this new generation of rain accumulation is the correction of ground clutter with several elevation angles of the radar beam to rise above the terrain when necessary. Thus there was an almost complete disappearance of ground clutter on the territory of Greater Lyon, with the exception of the pixel corresponding to the highest peak (Figs. 3 and 4).

\subsection{Surface and local comparison based on accumu- lated precipitation of rainfall event on the Greater Lyon}

One of the improvements of the Panthere program is the hourly adjustment of these rain accumulations using rainfall data existing into the radar coverage. Thus, the differ- ences between results obtained by using the rainfall network of Greater Lyon and the radar are much smaller than the previous generation of rain accumulation. This comparison focused on the accumulation of July 2008, and on episodes of intense rainfall: the $3 \mathrm{rd}$, 6th, 11th and 26th of this month.

However, it is always necessary to adjust the radar values by a corrective coefficient obtained from the Greater Lyon rain gauges, to ensure equality between the accumulated precipitation measured by rain gauges and the one estimated by radar. The local comparison also gives better results. Thus, the relative average differences corresponding to the four intense episodes of July 2008 was only $14.1 \%$ (Table 1), compared to $37.6 \%$ of Hydram rain accumulation for that type of rainfall events.

\section{Conclusions}

The hydrological measurement quality of the Lyon radar over the territory of the urban community has evolved considerably since the early 90s. This radar, at first, produced data of uncertain quality when based on the Satolas site because of too many ground clutter related to a very low position in altitude. When moved to St. Nizier (920 m a.s.1.), Hydram rain accumulations provided improved measurements, despite any interference from local ground clutter.

Indeed, the average difference between these rain accumulations and the values obtained using Greater Lyon rain gauges is $20.4 \%$. The latest generation of rain accumulation (Panthere) has nearly eliminated the problem of ground clutter, with the exception of a single pixel, with different elevations of the angle of the radar beam now being available. Finally, the values provided by the radar are very close to those obtained with the network rainfall, even during exceptionally intense rain events, with $14.1 \%$ average difference. 

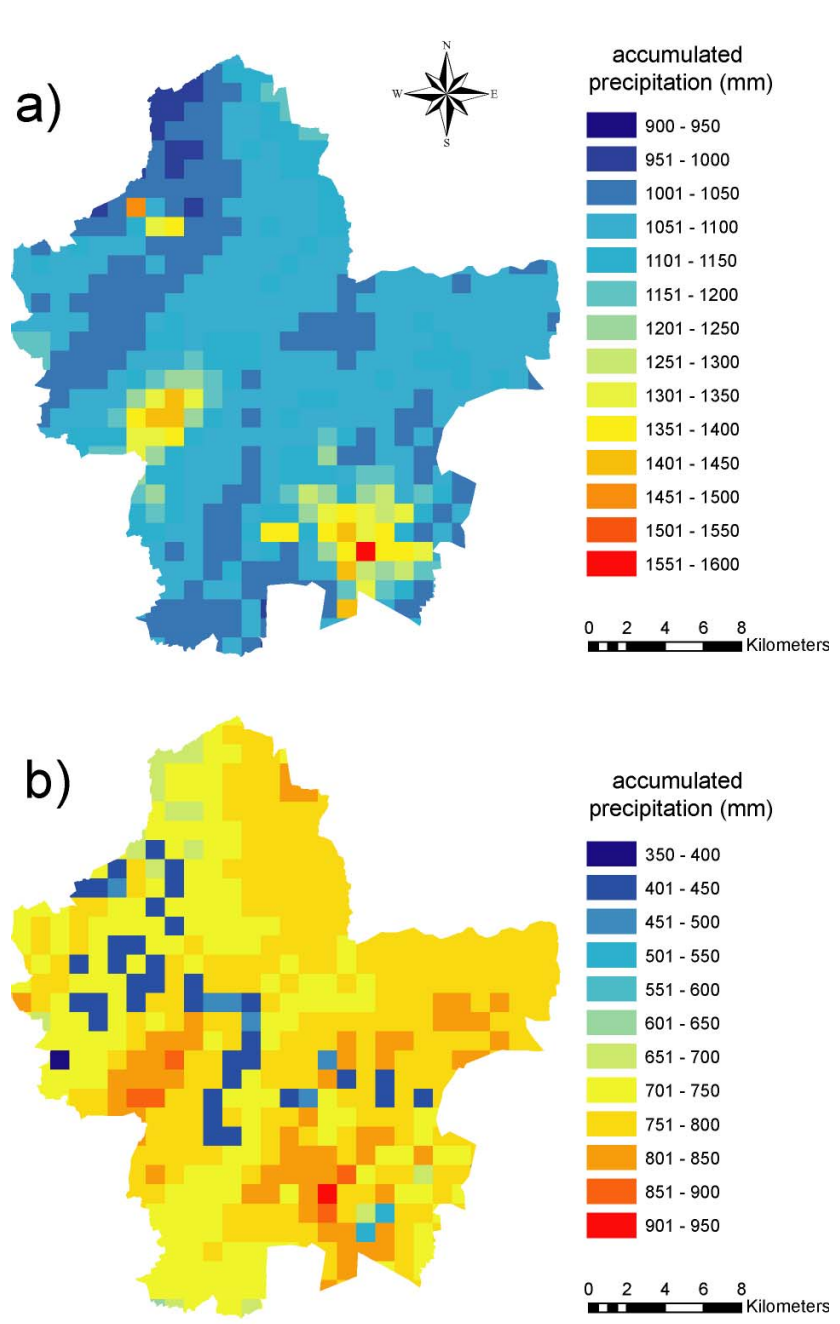

accumulated precipitation $(\mathrm{mm})$ $350-400$ $401-450$ $451-500$ $501-550$ $551-600$ $601-650$ $651-700$ $701-750$ $751-800$ $801-850$ $851-900$ $901-950$
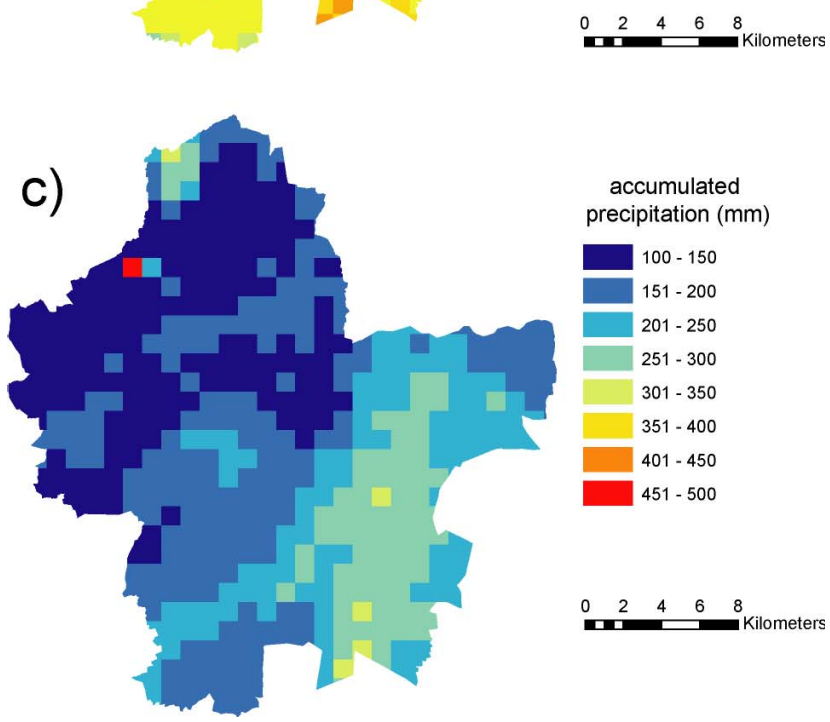

accumulated precipitation (mm)

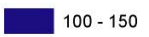
$151-200$ $201-250$ $251-300$ $301-350$ $351-400$ $401-450$ - $451-500$

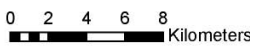

Edited by: S. C. Michaelides

Reviewed by: two anonymous referees

\section{References}

Chapon, B., Delrieu, G., Gosset, M., and Boudevillain, B.: Variability of raindrop size distribution and its effect on the Z-R relationship: A case study for intense Mediterranean rainfall, Atmos. Res., 87, 52-65, 2008.

Creutin, J. D., Borga, M., Lutoff, C., Scolobig, A., Ruin, I., and Créton-Cazanave, L.: Catchment dynamics and social response during flash floods: the potential of radar rainfall monitoring for warning procedures. Meteorol. Appl., 16, 115-125, 2009.

Delrieu, G., Boudevillain, B., Nicol, J., Chapon, B., Kirstetter, P. E., Andrieu, H., and Faure, D.: Bollène 2002 experiment: radar rainfall estimation in the Cevennes-Vivarais region, J. Appl. Meteorol. Clim., 48, 1422-1447, 2009.

Delrieu, G., Creutin, J.D., and Andrieu, H.: Simulation of X-band weather radar mountain returns using a digitized terrain model, J. Atmos. Ocean. Tech., 12, 1038-1049, 1995.

Faure, D.: Rapport ALICIME RE05002b, Cartographie globale de la visibilité hydrologique du réseau radar métropolitain ARAMIS à l'horizon 2006: Extension à l'ensemble du territoire métropolitain pour le mode d'exploitation passé et actuel des radars, 50 p, 2005.

Faure, D.: Rapport ALICIME RE05001, Cartographie globale de la visibilité hydrologique du réseau radar métropolitain ARAMIS à l'horizon 2006 : Mise au point des méthodes de calcul, d'optimisation du protocole de balayage et de combinaison radar-radar, sur la région Sud Est de la France, 27 p, 2006.

Météo-France, Direction des Systèmes d'Observation: Documents sur la qualité de mesure du radar ARAMIS de Lyon Satolas, et cartographie des échos fixes et des masques observés sur les images de ce radar, $31 \mathrm{p}, 2001$.

Michelson, D., Einfalt, T., Holleman, I., Gjertsen, U., Friedrich, K., Haase, G., Lindskog, M., and Jurczyk, A.: Weather radar data quality in Europe quality control and characterisation. Review, COST Action 717 - Use of radar observations in hydrological and NWP models, Luxembourg, 87 p, 2005.

Pellarin, T. : Visibilité hydrologique de radars météorologiques opérant en régions montagneuses: application au bassin versant de l'Ardèche, $\mathrm{PhD}$ of the Joseph Fourier University, Grenoble I, 253 p, 2001.

Pellarin, T., Delrieu, G., Saulnier, G.M., Andrieu, H., Vignal, B., and Creutin, J.D.: Hydrologic visibility of weather radar systems operating in a mountainous region: case study for the Ardèche catchment (France), J. Hydrometeor., 3, 539-555, 2002.

Renard, F. and Chapon, P.-M.: Evaluation de la vulnérabilité urbaine pour une approche globale du risque: utilisation d'une méthode d'aide à la décision et application à l'agglomération lyonnaise. L'Espace géographique, $\mathrm{n}^{\circ} 1$, 35-50, 2010.

Renard, F. and Comby, J.: Caractérisation de l'aléa pluviométrique en milieu urbain à partir d'interpolations spatiales: le cas du Grand Lyon, Climatologie, 4, 131-144, 2007.

Fig. 4. Same as Fig. 3 but with a zoom on the Greater Lyon. 